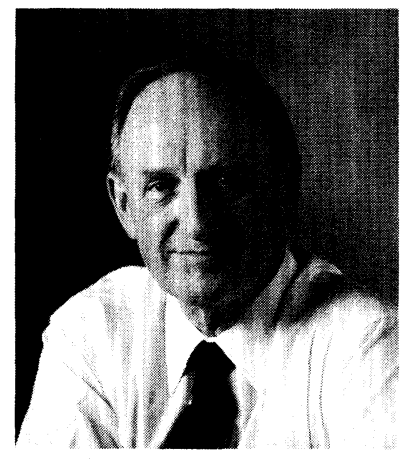

\section{The Anatomy of an Invitation}

There is a certain distinction in the scientific and engineering world in recording that a particular piece of published work is "invited" as opposed to "submitted," even though both kinds of articles, chapters, or papers are subjected to the identical review process. The same is true for conference papers that are to be presented orally; the conference program will usually "feature" the "invited" speaker. Some presentations have the added acclaim of being "keynote addresses." I do not deny or denigrate those processes in our culture and have often basked in the momentary glory of being "invited" and retain that fleeting pleasure as a memory permanently engraved in my résumé.

However, real life is a little more complicated than it seems: one can be really "Invited" or merely "invited."

Recourse to a current dictionary ${ }^{1}$ reveals that the verb, to invite, has several shades of meaning. For example:

'in'vite lin-'vite $v t$ in.vited; in-vit.ing [MF or L; MF inviter, fr. L. invitare] 1 a: to offer an incentive or inducement to: ENTICE b: to increase the likelihood of 2a: to request the presence or participation of $\mathbf{b}$ : to request formally c: to urge politely: welcome - in.viter $n$ syn INVITE, SOLICIT, COURT shared meaning element: to request or encourage to respond or act.

The first meaning is interesting; some authors are indeed invited to prepare a review article or a book chapter with a modest financial incentive being provided in the form of an honorarium. On other occasions the inducement is a royalty. The financial rewards, though exceedingly modest in our field, presumably do increase the likelihood of our involvement in that particular publication. (I should note that your journal Optical Engineering never provides those, or any other kind of financial incentive.)

The invitation to speak at a conference is usually "to request the presence or participation of" the invitee. On somewhat rare occasions there might be some inducement in the form of assistance with travel expenses and on even more rare occasions, a token honorarium.

An invitation that is "to request formally" your attendance is a dying art at the personal level (apart from

${ }^{1}$ Webster's New Collegiate Dictionary, G \& C Merriam Co., Springfield, Mass. weddings), mainly, perhaps, because the particular art form has been taken over by the fund-raisers of this world, who "formally" invite us with very fancy invitations to part with (contribute) significant monies to participate in the eventseveral distinctive levels of sponsorship are offered. If the formal invitation is a dying art, then the formal response is dead already. Putting RSVP on an invitation does not seem to awaken the response it calls for! (But that is the subject of an interesting social essay unto itself.)

I particularly like the last meaning, "to urge politely." And hence, back to Optical Engineering. We do not have "invited" papers in the earlier meaning of the word. However, our guest editors do "urge" their colleagues to prepare papers for submission to the special sections of the journal for which they are responsible. I hope that the urging is polite, but do not necessarily demand that it is! These invitations are really solicitations to submit your work for consideration for publication in the special section. The pleasure and satisfaction must come from preparing the paper and sharing the results of your work with the extended readership of Optical Engineering. Thus is knowledge gained and shared and the field moved along in small but definite and distinctive steps. For that privilege we even solicit (invite) you to pay the page charges. Sorry about that necessity! As editor I look forward to reading and publishing your work. I "invite" you to submit your work to Optical Engineering.

\section{Editor's Anecdote: The Anxious Author}

I received the following items in the order presented here.

Fax 12:30 p.m., 24 Dec. "These pages should have accompanied my last mailing (yesterday by overnight U.S. Postal Service)."

Letter dated 23 Dec. and received by special delivery from the U.S. Postal Service on Christmas Day (25 Dec.). "I am sending you my responses to the reviewers' comments and suggestions which should have been enclosed with the revised manuscript that was sent to you yesterday."

Letter dated 22 Dec., received 30 Dec. "Please find enclosed the original and a copy of my revised manuscript."

Happy outcome. It all came together and the paper was accepted on 3 January 1995. 
June 1995

Polarization Analysis and Measurement

Dennis H. Goldstein

WL/MNGA

101 West Eglin Boulevard, Suite 280

Eglin AFB, FL 32542

904/882-4636 ext. 2399 904/882-4034 FAX

E-mail: goldstei@eglin.af.mil

David B. Chenault

Naval Research Laboratory

Code 5622, Optical Sciences

4555 Overlook Avenue

Washington, DC 20375-9998

202/767-0390 202/767-6370 FAX

E-mail: chenault@nrlfs1.nrl.navy.mil

Russell A. Chipman

University of Alabama in Huntsville

Physics Department, Optics Building 318

Huntsville, AL 35899

205/895-6417 ext. 318 205/895-6873 FAX

E-mail: chipmanr@email.uah.edu

July 1995

Optics in Switzerland, Part 1: Federal

Institutes of Technologies

P. K. Rastogi

Swiss Federal Institute of Technology-Lausanne

Laboratory of Stress Analysis

CH-1015 Lausanne

Switzerland

E-mail: rastogi@elgc.epfl.ch

(021) $6932445 \cdot(021) 6934748$ FAX

August 1995

Photorefractive Nonlinear Optics

Partha P. Banerjee

University of Alabama in Huntsville

Department of Electrical and Computer Engineering

Huntsville, AL 35899

205/895-6215 ext. 416 • 205/895-6880 FAX

Optics in Switzerland, Part 2: Universities and Research Institutes

P. K. Rastogi

Swiss Federal Institute of Technology-Lausanne

Laboratory of Stress Analysis

$\mathrm{CH}-1015$ Lausanne

Switzerland

E-mail: rastogi@elgc.epfl.ch

(021) $6932445 \cdot(021) 6934748$ FAX

September 1995

Optical Science and Engineering in Finland

Seppo Honkanen

Nokia Research Center

P.O. Box 45

FIN-00211 Helsinki

Finland

+35804376471 •+35804552557 FAX
Optics in Switzerland, Part 3: Industries and Observatories

P. K. Rastogi

Swiss Federal Institute of Technology-Lausanne

Laboratory of Stress Analysis

$\mathrm{CH}-1015$ Lausanne

Switzerland

E-mail: rastogi@elgc.epfl.ch

(021) $6932445 \cdot(021) 6934748$ FAX

November 1995

Optical Remote Sensing and Image

Processing

Mohammad A. Karim

Bradley D. Duncan

University of Dayton

Center for Electro-Optics

300 College Park

Dayton, OH 45469-0227

$513 / 229-2241 \cdot 513 / 229-3177$

513/229-2471 FAX

\section{December 1995}

Optics in Polymer Science and Technology

Maksymilian Pluta

Institute of Applied Optics

Kamionkowska 18

03-805 Warsaw, Poland

(4822) $184405 \cdot(4822) 133265$ FAX

Andrzej Wasiak

Institute of Fundamental Technological Research

Polish Academy of Sciences

Savietokrzyska 21

00-012 Warsaw, Poland

(4822) 269815 FAX

\section{January 1996}

Optical Science and Engineering in Argentina

Guillermo H. Kaufmann

Universidad Nacional de Rosario

Instituto de Fisica Rosario

Applied Optics Group

Bv. 27 de Febrero 210 bis

2000 Rosario

Argentina

E-mail: guille@ifir.edu.ar

or gkaufman@arosario.bitnet

5441825838 • 5441257164 FAX

Manuscripts due June 1, 1995

Visual Communications and Image

Processing

Cheng-Tie Chen

Bellcore, NVC 3X-321

331 Newman Springs Road

Red Bank, NJ 07701

908/758-3106 • 908/758-4371 FAX

E-mail: ctc@nyquist.bellcore.com

Kou-Hu Tzou

COMSAT Laboratories

22300 Comsat Drive

Clarksburg, MD 20871

301/428-4663 - 301/428-9287 FAX

E-mail: kouhu@ctd.comsat.com
Ya-Qin Zhang

GTE Laboratories

40 Sylvan Road

Waltham, MA 02254

617/466-2259 • 617/890-9320 FAX

E-mail: yz00@gte.com

Manuscripts due June 1, 1995

\section{February 1996}

Optical Engineering in Small Companies

Xiangyang Yang

University of New Orleans

Department of Electrical Engineering

New Orleans, LA 70148

504/286-5524 • 504/286-3950

E-mail: xxy@uno.edu

William J. Miceli

Office of Naval Research

800 North Quincy Street

Arlington, VA 22217-5000

703/696-5752 • 703/696-1330 FAX

Manuscripts due July 1, 1995

March 1996

Sensor Fusion

Belur V. Dasarathy

Dynetics, Inc.

P.O. Box Drawer B

Huntsville, AL 35814-5050

205/922-9230 ext. $355 \cdot 205 / 922-9219$ or

205/922-9260 FAX

E-mail: belur@dynetics.com

Manuscripts due Aug. 1, 1995

May 1996

Optical Engineering in Romania

Adrian Podoleanu

University of Kent at Canterbury

Physics Laboratory

Kent CT2 7NR

United Kingdom

$0227764000 \quad 0227475423$ FAX

E-mail: ap11@ukc.ac.uk

Manuscripts due Sep. 1, 1995 